\title{
PERCEPÇÃO AMBIENTAL E PAISAGISMO ECOLÓGICO NO ENSINO FUNDAMENTAL: FERRAMENTAS IMPORTANTES PARA PROMOÇÃO DA EDUCAÇÃO AMBIENTAL NO CONTEXTO ESCOLAR
}

\author{
Maria Eunice da Silva Martins ${ }^{1}$ \\ Josiane Teresa Nicácio Rocha² \\ Lázaro Rodrigues Tavares ${ }^{3}$ \\ Leonardo Rafael Medeiros ${ }^{4}$
}

Resumo: $O$ paisagismo ecológico é uma prática que tem por finalidade produzir jardins sustentáveis que possibilitem a restauração harmônica de espaços de forma a não interferir no meio ambiente, sendo uma oportunidade promissora de efetivação da Educação Ambiental. Este trabalho objetivou investigar, a partir de uma pesquisa-ação, a percepção ambiental de alunos do Ensino Fundamental I e proporcionar reflexões acerca da sustentabilidade a partir da construção coletiva e participativa de um jardim ecológico no ambiente escolar. Foram utilizadas espécies nativas e adaptadas à Caatinga, bem como foram construídos vasos e ornamentos com materiais reutilizados. As intervenções apresentaram notório êxito, evidenciado na mudança significativa da consciência das crianças sobre a importância da preservação do meio ambiente.

Palavras-chave: Jardim Ecológico; Sustentabilidade; Pesquisa-Ação; Cactáceas; Materiais Reutilizados.

${ }^{1}$ Instituto Federal do Rio Grande do Norte, campus Ipanguaçu. E-mail: eunicemartins17@hotmail.com 2 Instituto Federal do Rio Grande do Norte, campus Ipanguaçu. E-mail: josianeteresa05@gmail.com 3 Instituto Federal do Ceará, campus Tabuleiro do Norte. E-mail: lazarortavares@gmail.com ${ }^{4}$ Instituto Federal do Rio Grande do Norte, campus Ipanguaçu. E-mail: leonardo.rafael@ifrn.edu.br Revbea, São Paulo, v.16, № 1: 472-492, 2021. 
Abstract: Ecological landscaping is a practice whose purpose is to produce sustainable gardens that enable the harmonious restoration of spaces in a way that does not interfere with the environment, therefore being a promising opportunity for carrying out Environmental Education. This work aimed to investigate, through an action research, the environmental perception of elementary school students and provide reflections on sustainability from the collective and participative construction of an ecological garden at school. Native species adapted to Caatinga were used, as well as vases and ornaments were constructed with reused materials. The interventions were notoriously successful, evidenced by the significant change in the awareness of children about the importance of preserving the environment.

Keywords: Ecological Garden; Sustainability; Action Research; Cacti; Reused Materials.

\section{Introdução}

Uma das práticas mais antigas da humanidade, cujo objetivo sempre esteve voltado para proporcionar o bem-estar humano, é o paisagismo. Essa atividade existe desde a Pré-História, momento em que o homem mantinha uma relação harmoniosa e equilibrada com a natureza, e era utilizada sobretudo para ornamentar os espaços externos com cores, texturas e técnicas profissionais. Diante dessa perspectiva, é notório o fato de que uma paisagem agradável é fundamental para conferir beleza e suavidade a locais públicos, estando intimamente relacionada à qualidade de vida e tranquilidade emocional (GENGO; HENKES, 2013; SANTOS, 2009).

Apesar de o paisagismo ter surgido em um cenário diferente na história da humanidade, a relação do homem com o meio ambiente, na modernidade, vem sendo marcada por intensos desequilíbrios, principalmente após o século XVIII com a Revolução Industrial, a qual trouxe grandes mudanças na forma como o ser humano convive com os recursos naturais (DIAS, 2010). As consequências da industrialização geraram profundas transformações no modo de vida das pessoas e das cidades, cujos impactos são perceptíveis no meio ambiente, notadamente com o aumento da poluição, do desflorestamento e da extinção da biodiversidade, bem como com o advento do consumismo, do desperdício e das mudanças climáticas globais (MARTINE; ALVES, 2015).

Diante de tantos desastres naturais, existe uma constante busca para minimizar e mudar esse estilo de vida das pessoas, que exaure os recursos naturais e é uma ameaça à própria qualidade de vida. Desse paradoxo existente na inserção do homem no meio ambiente, surge o paisagismo ecológico, uma vertente dentro do paisagismo que se preocupa em produzir jardins sustentáveis, com a finalidade de restaurar espaços, conferindo-lhes cor e vida, de forma a não interferir no meio ambiente. Essa prática busca alternativas importantes para possibilitar a preservação da natureza a partir de 
gestos e ações que beneficiem o planeta e promovam o aumento da qualidade de vida (MEDEIROS, 2008).

Uma das características do paisagismo ecológico é a valorização do bioma em que ele está inserido, especificamente com a utilização de espécies da flora próprias da região, mantendo, assim, a personalidade do bioma. Além disso, essa prática incorpora princípios de sustentabilidade, como a adoção de técnicas que minimizem o desperdício de água, evitem a degradação do solo e - gasto desnecessário de resíduos, não utilizem adubação química e não interfiram negativamente na fauna local (MOTA et al., 2013; EMER et al., 2011).

Apesar de bastante disseminado no Brasil e no mundo, o paisagismo ecológico não é uma atividade fácil, tendo em vista que as condições ambientais em que as plantas são cultivadas interferem no seu desenvolvimento. Assim, verifica-se que essa prática é pouco difundida nas cidades dentro do bioma da Caatinga, haja vista que a escassez hídrica, característica do clima semiárido, é um dos grandes fatores que dificultam a promoção do paisagismo (MEIRA et al., 2017). Na prática, o que se observa é a adoção generalizada de espécies invasoras, como o nim indiano (Azadirachta indica) e o fícus (Ficus benjamina), os quais oferecem ameaças à biodiversidade local. Além de essas espécies descaracterizarem a região, uma vez que são excelentes competidoras e impedem o estabelecimento de plantas nativas, também afugentam a fauna local (MORO et al., 2013; ZEA et al., 2015).

Dessa maneira, fica evidente que um dos principais motivos para o insucesso de projetos paisagísticos, sobretudo no semiárido brasileiro, é a falta de conhecimento na hora de decidir quais espécies são mais adequadas e que técnicas de manejo devem ser utilizadas. É importante levar em consideração diversos fatores para o plantio, tanto ambientais - como disponibilidade de água e taxa de incidência luminosa - quanto aspectos da própria planta - tais como cor, textura e tamanho (ALVAREZ; KIILL, 2014). Diante disso, uma alternativa promissora para o clima semiárido, que possibilita a superação das limitações hídricas impostas pelo bioma, é a adoção de cactáceas, plantas que pertencem à família Cactaceae. Essas espécies oferecem resistência a climas quentes e secos por apresentarem um armazenamento interno de água, raízes profundas e folhas modificadas em espinhos, os quais minimizam a perda de água e, consequentemente, diminuem a evapotranspiração (SALVIATÍ, 1993; LEAL et al., 2005). Destarte, a adoção de cactáceas, além de valorizar a Caatinga, minimiza os gastos com irrigação, sendo, portanto, uma alternativa sustentável.

Outra prática comum em jardins ecológicos é a utilização de materiais reutilizados, principalmente dentro de espaços escolares. Essa opção, além de economicamente viável, é benéfica ao meio ambiente, pois o descarte incorreto do lixo, proveniente das atividades humanas, é uma das grandes problemáticas do mundo moderno (POLLI; SOUZA, 2013). Contudo, é sabido que, desse lixo, boa parte dos materiais pode ser reaproveitada como matéria-prima para Revbea, São Paulo, v.16, № 1: 472-492, 2021. 
confecção de produtos que podem ser utilizados na ornamentação. Essa fração reaproveitável do lixo, que é chamada de resíduo sólido, é sustentável e permite a ressignificação do lixo produzido pelo ser humano (CINQUETTI, 2004).

Como o paisagismo ecológico toma como base os princípios da sustentabilidade, percebe-se que essa prática pode ser utilizada como ferramenta nos estudos de Educação Ambiental (EA), em especial no âmbito escolar, uma vez que se apresenta como uma excelente proposta de se discutir não somente sustentabilidade, mas também ecologia e conservação (SAFT et al., 2011). No tocante à Educação Infantil, abordar temas relacionados ao meio ambiente, como reciclagem, paisagismo e impactos humanos, é fundamental para a construção inicial de uma consciência voltada à preocupação com a preservação do meio ambiente e exercício da cidadania, na perspectiva de solucionar problemas cotidianos (MEDEIROS et al., 2011). O processo de conscientização a partir da práxis e da investigação dos problemas do cotidiano é extremamente relevante, tendo em vista que promove o desenvolvimento crítico por meio da tomada de consciência, permitindo, assim, a mudança da realidade (FREIRE,1979). Com o paisagismo, especificamente, é possível sensibilizar alunos sobre a importância das áreas verdes e do contato com os elementos da natureza nos centros urbanos para o nosso bem-estar, saúde psicológica e qualidade de vida (GUMY; BOBROWSKI, 2016).

Trabalhar a temática ambiental nos primeiros anos da escola de forma prática traz benefícios para o desenvolvimento da criança e deixa também marcas duradouras. Isso ocorre porque o meio ambiente saudável fornece estímulos sensoriais importantes para a criação de um sentimento de pertencimento, provocando reações emocionais que ensinam a valorizar e amar. Esse elo emocional desde criança é fundamental para construir significações no futuro (TUAN, 1974 apud BARBOSA, 2010). Percebe-se, portanto, que a presença de espaços verdes dentro da escola infantil fornece benefícios não somente para melhorar a qualidade ambiental, através da amenização do clima e da beleza cênica, mas também para transformar o espaço em um ambiente acolhedor, aconchegante, de personalidade e convidativo à aprendizagem (FAGUNDES et al., 2015; RIBEIRO et al., 2012).

Diante da importância de se trabalhar assuntos relacionados ao meio ambiente com crianças em fase escolar, bem como da relevância do paisagismo ecológico para a melhoria da qualidade ambiental, objetivou-se conscientizar alunos do Ensino Fundamental I de uma escola municipal da cidade de Angicos, no Rio Grande do Norte, a partir de reflexões sobre a importância da preservação do meio ambiente. Sendo assim, o presente trabalho teve o intuito de investigar a percepção ambiental dos alunos, a fim de possibilitar maiores discussões acerca da sustentabilidade ambiental com a construção coletiva e participativa de um jardim ecológico na escola. 


\section{Metodologia}

\section{Tipo de pesquisa}

A produção de conhecimentos, para Thiollent (1986), é gerada conforme ações de investigação científica, as quais partem da observação de situações para a tomada de decisões e transformação dos fatos. Dessa maneira, é relevante articular o método de análise de nossa pesquisa com a problemática levantada, pois auxiliará na compreensão da situação-problema, orientando o direcionamento do estudo. A partir dessa ótica, decidimos utilizar, como método de investigação deste trabalho, a pesquisa-ação, que, de acordo com Ghedin e Franco (2008), é um tipo de pesquisa que se origina a partir das necessidades sociais reais de um grupo e está vinculada ao meio natural de vida, o que implica na participação dos sujeitos envolvidos no processo. Nessa perspectiva, é atribuído ao pesquisador tanto o papel de pesquisador como de participante. Com a pesquisa-ação, pretende-se alcançar realizações, ações efetivas, transformações ou mudanças no campo social (THIOLLENT, 1986). Além disso, a pesquisa apresenta uma abordagem qualitativa, de natureza aplicada.

\section{Contexto de pesquisa}

O presente trabalho foi realizado na Escola Municipal Espedito Alves (EMEA), de agosto de 2019 a março de 2020. A escola fica localizada no município de Angicos, pertencente à mesorregião do Central Potiguar do Estado do Rio Grande do Norte (IBGE, 1990). O município apresenta uma população estimada de 11.714 habitantes, extensão territorial de $741,582 \mathrm{~km}^{2} \mathrm{e}$ clima tropical semiárido (IBGE, 2019). A referida escola tem um total de 62 matrículas realizadas na pré-escola, 158 no Ensino Fundamental I ( $1^{\circ}$ ao $5^{\circ}$ ano) e 3 de Educação Especial.

Inicialmente, foi feita uma visita à escola no início do mês de agosto, momento em que foram observados o ambiente e a infraestrutura escolar. Por ser uma instituição de Educação Infantil, constatamos que a área não era adequada para a convívio e lazer das crianças, devido à degradação de algumas estruturas, à presença de grandes áreas vazias sob intensa incidência solar, à pouca cobertura vegetal e à ausência de espaços de convivência satisfatórios para realização de atividades extraclasse (Figura 1). 


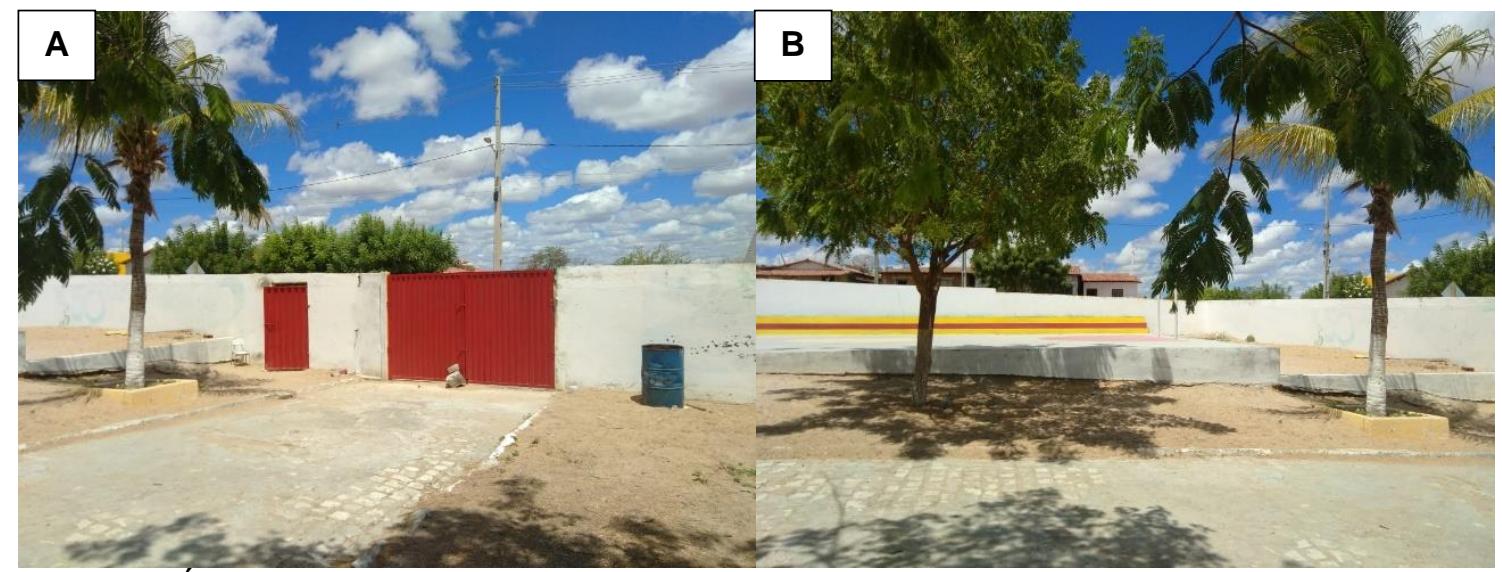

Figura 1: Área interna da EMEA. A: Vista interna da entrada da escola; B: Principal corredor de acesso às salas de aula. Ao fundo, encontra-se a quadra de esporte sem cobertura.

Fonte: Autoria própria.

Foi possível perceber que as dificuldades enfrentadas pela escola eram decorrentes, dentre outras questões, da falta de iniciativa da instituição em realizar mudanças e da falta de recursos para a concretização dessas ações. Tendo isso em vista, optou-se pela utilização de materiais de baixo custo e de parcerias com outras instituições para a construção do jardim ecológico. Além disso, seguindo a prática da pesquisa-ação, foi feito um esforço para realizar um trabalho conjunto entre o pesquisador e os grupos implicados - neste caso, os alunos da escola - focando, assim, no papel ativo desses estudantes durante toda a pesquisa.

\section{Etapas metodológicas}

O passo inicial foi a certificação da viabilidade de uma intervenção do tipo pesquisa-ação no meio considerado, levando em consideração a opinião dos interessados e suas expectativas. Assim, antes de iniciarmos a realização das ações de fato, foi decidido, em conversa com os gestores da escola, que a turma escolhida seria a do $3^{\circ}$ ano do período da tarde, a qual apresentava um total de 17 alunos, de 8 a 9 anos, uma vez que os estudantes eram bastante comunicativos e participativos.

Ao todo, foram realizados 22 encontros presenciais divididos em 6 etapas: i) aplicação do questionário inicial; ii) intervenções com a turma; iii) construção do jardim ecológico; iv) visita técnica ao Instituto Federal de Educação, Ciência e Tecnologia do Rio Grande do Norte, campus Ipanguaçu (IFRN/IP); v) aplicação do questionário de satisfação; vi) acompanhamento do projeto (Quadro 1). 
Quadro 1: Cronograma de encontros para aplicação da pesquisa-ação com alunos da EMEA.

\begin{tabular}{|c|c|c|}
\hline & Abordagem teórica & Dinâmica/Atividade prática \\
\hline Encontro 1 & Aplicação do questionário inicial & - \\
\hline Encontro 2 & Tema: Educação Ambiental & Quiz de perguntas e respostas \\
\hline Encontro 3 & Tema: Meio ambiente & Roda de conversa \\
\hline Encontro 4 & Tema: Cactáceas e suculentas & Jogo de verdadeiro ou falso \\
\hline Encontro 5 & - & $\begin{array}{c}\text { Confecção de vasos a partir de } \\
\text { resíduos sólidos reutilizados }\end{array}$ \\
\hline Encontro 6 & Tema: Sustentabilidade & Caça ao tesouro \\
\hline Encontro 7 & - & $\begin{array}{c}\text { Confecção de vasos a partir de } \\
\text { resíduos sólidos reutilizados }\end{array}$ \\
\hline Encontro 8 & Tema: Reciclagem e coleta & Jogo da coleta seletiva \\
\hline Encontro 9 & Tema: Paisagismo ecológico & Desenho e pintura \\
\hline Encontro 10 ao 19 & - & Construção do jardim ecológico \\
\hline Encontro 20 & Aplicação do questionário de & Visita técnica ao IFRN/IP e \\
satisfação & - \\
\hline Encontro 21 & Acompante de mudas \\
\hline Encontro 22 & Acompanhamento do projeto & - \\
\hline
\end{tabular}

Fonte: Autoria própria.

A primeira etapa, mais exploratória, consistiu na realização de um diagnóstico da situação, dos problemas prioritários e de eventuais ações para a melhoria do ambiente na escola. Nessa fase, foi aplicado um questionário inicial semiestruturado, contendo 6 questões. A finalidade desse questionário foi avaliar a percepção ambiental e os conhecimentos prévios dos alunos antes da aplicação do projeto em relação aos assuntos meio ambiente e sustentabilidade, para guiar as ações e temáticas a serem trabalhadas com os alunos ao longo da pesquisa-ação. Além disso, a turma foi dividida em grupos, os quais tinham a incumbência de trazer materiais reutilizáveis ao longo de todo o projeto (garrafas pet, papelão, latas, CDs etc.), os quais seriam utilizados para a confecção do jardim ecológico.

A segunda etapa consistiu em 8 encontros semanais, de duração de 1 hora cada, no turno inverso às aulas dos estudantes. Cada intervenção era dividida em dois blocos: um teórico, em que eram abordados temas diversos da área de meio ambiente e paisagismo; e outro prático, em que eram desenvolvidas atividades lúdicas, como gincanas, brincadeiras, elaboração de desenhos e quizzes sobre o assunto abordado no dia (Quadro 1). É importante salientar que dois dos encontros não contemplaram a parte teórica, tendo em vista que foi preciso mais tempo para realização da parte prática.

Em seguida, na terceira etapa, foram realizados 10 encontros presenciais, cujo objetivo era construir o jardim ecológico. Como os alunos foram incentivados a trazer materiais reutilizáveis desde o primeiro dia, uma grande quantidade de recursos estava à disposição para ser utilizada por eles na confecção de vasos, suportes e objetos de decoração. Além disso, foram disponibilizados pneus para a produção do jardim e de algumas trilhas. Mudas de cactos e outras espécies suculentas, bem como $150 \mathrm{~kg}$ de substrato 
orgânico (composto por barro e esterco, numa proporção de 2:1), foram cedidos pelo IFRN/IP. Ao todo, foram usadas 25 mudas de onze-horas (Portulaca grandiflora), 20 cactos castelo de fada (Acanthocereus tetragonus), 15 agaves (Agave sp.), 10 flores de dragão (Huernia sp.) e 20 babosas (Aloe vera).

$\mathrm{Na}$ quarta etapa, um último encontro foi feito a partir de uma visita técnica ao IFRN/IP, o qual é uma renomada instituição pública de ensino federal, conhecida como campus verde e por apresentar cursos na área ambiental, como técnico em agroecologia e técnico em meio ambiente. A instituição conta com uma fazenda-escola, composta por vacaria, aprisco, aviário, pomar, estufa e viveiro de mudas, onde são aplicadas técnicas agroecológicas de cultivo de sementes e manejo de animais. Nessa ocasião, as crianças tiveram a oportunidade de conhecer todos os ambientes da fazenda-escola, bem como de assistir a uma aula prática com a realização de um transplante de mudas de hortaliças. Ao finalizar a visita, foi realizada a quinta etapa do projeto, com a aplicação de um questionário de satisfação, cujo objetivo foi avaliar a aceitação e apreciação dos alunos em relação ao projeto como um todo.

Posteriormente, com o intuito de observar os efeitos das intervenções a médio prazo, foram realizadas duas visitas à escola nos meses de fevereiro e março de 2020. Nesses dois momentos, foi observado o estado de conservação do jardim e foi verificado o que os estudantes tinham aprendido com o projeto, a partir de uma conversa informal com os gestores, professoras e demais alunos.

\section{Resultados e discussão}

\section{Análise do questionário inicial}

Antes da aplicação do projeto, observou-se que 16 alunos (94\%) nunca tinham ouvido falar sobre sustentabilidade, ao passo que apenas 1 (6\%) afirmou conhecer $\mathrm{O}$ assunto, destacando que seria "a melhoria do nosso ambiente" (Figura 2A). Quando questionados acerca do conceito dos 3Rs (Reduzir, Reutilizar e Reciclar), a turma ficou dividida, pois $9(53 \%)$ deles asseveraram desconhecer o conceito, ao passo que 8 (47\%) responderam positivamente e conseguiram identificar corretamente o que representavam os 3Rs (Figura 2B). Ademais, dos 8 alunos que acertaram, 2 citaram também o "R" de Repensar, demonstrando conhecerem o conceito dos $5 R s$, que é uma ampliação da política dos $3 R$ s ao incorporar os princípios de Repensar e Recusar. As principais fontes de informação, segundo os alunos, sobre as questões ambientais foram através da internet (59\%), escola (59\%) e televisão (53\%). Nenhum aluno informou não ter acesso a essas informações (Figura 3). 


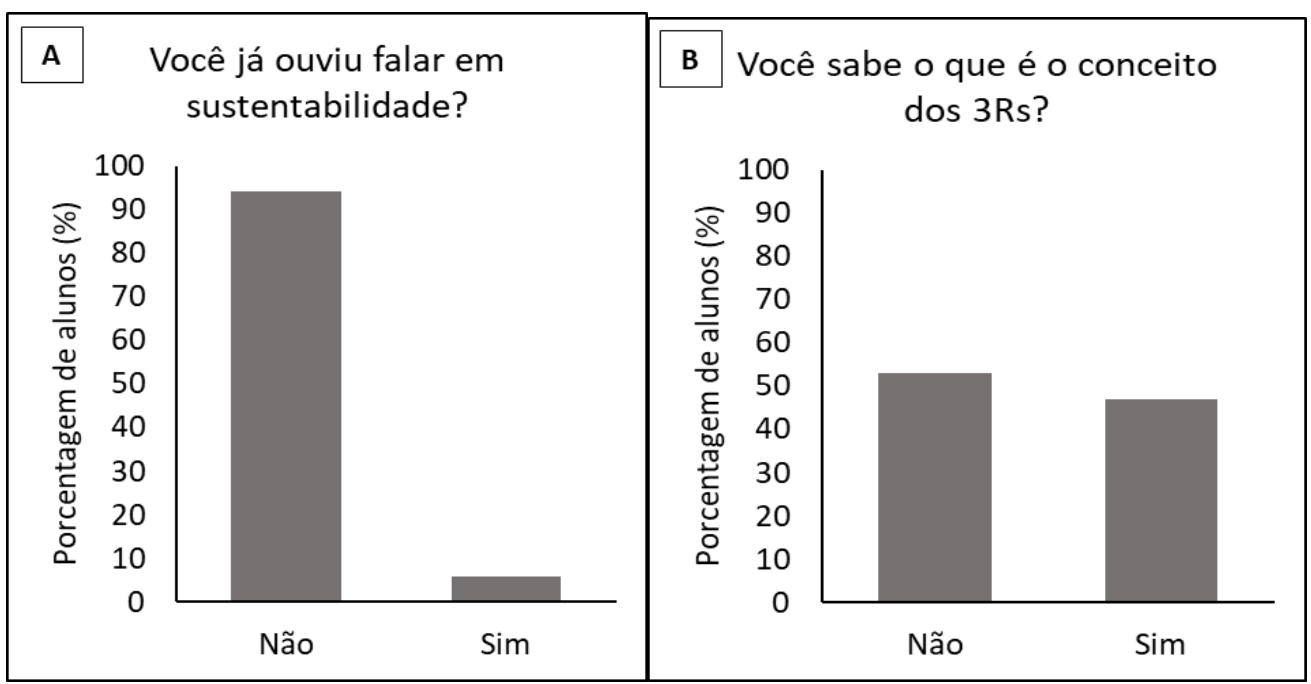

Figura 2: Conhecimento dos alunos a respeito de temas ambientais antes do projeto. A: "Você já ouviu falar em sustentabilidade?"; B: "Você sabe o que é o conceito dos 3Rs?"; N = 17.

Fonte: Autoria própria.

Esses resultados apontam que, apesar de praticamente a sala inteira afirmar nunca ter ouvido falar sobre sustentabilidade, os alunos demonstraram conhecer algumas ações ambientalmente conscientes, como a prática dos 3Rs. $O$ fato de dois estudantes terem citado, além dos 3Rs convencionais, o " $R$ " de Repensar reforça essa ideia e revela um elemento importante da consciência ambiental, uma vez que 0 ato de repensar perpassa pela reflexão sobre o nosso padrão de consumo, nossos hábitos cotidianos e reais necessidades (SILVA et al., 2017). A temática da sustentabilidade, abordada sobretudo em discussões em torno da problemática do lixo, é frequentemente trabalhada na Educação Infantil, sendo crucial para conscientizar as crianças e gerar reflexões a respeito dos impactos do lixo no ambiente (LINK et al., 2012).

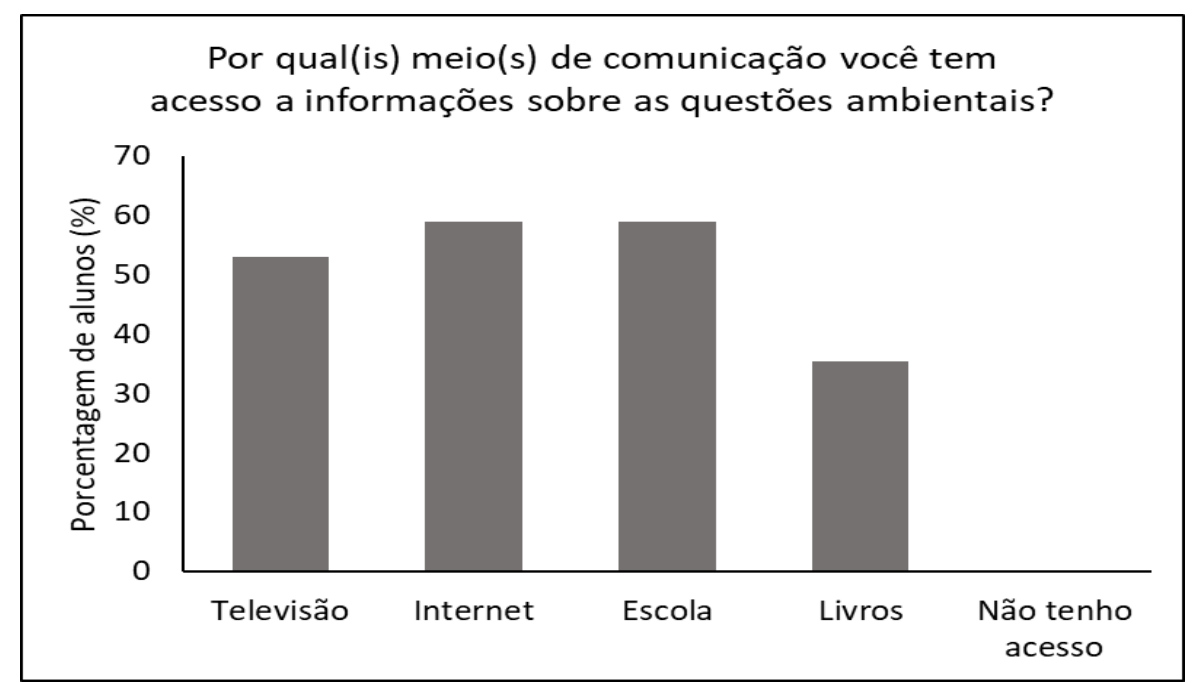

Figura 3: Levantamento sobre os principais meios de comunicação que fornecem informações sobre as questões ambientais para os alunos; $\mathrm{N}=17$.

Fonte: Autoria própria. 
A respeito do conceito de meio ambiente, apenas 13 alunos (76\%) responderam e suas respostas demonstraram uma visão de que meio ambiente se refere apenas à natureza (Quadro 2), concepção conhecida como naturalista (REIGOTA, 2012). Essa visão é aceitável para essa idade, uma vez que o conceito de meio ambiente é bastante complexo e que as crianças precisam conhecer a importância da natureza primeiro para, em seguida, saber como as sociedades se relacionam com o meio natural, sendo parte do meio ambiente. A concepção naturalista, amplamente difundida entre as crianças, se deve ao contato que elas têm com a natureza, incentivado através de ações nas escolas, desde a Educação Infantil. Essa aproximação aos elementos da natureza é de fundamental importância para o desenvolvimento da criança, pois garante uma melhoria na qualidade ambiental, fortalece o elo homemnatureza e auxilia na construção de valores sustentáveis (RAMBO; ROESLER, 2019). A visão naturalista do meio ambiente é importante nessa idade para que esse conceito possa ser trabalhado e ampliado nas séries mais avançadas.

A partir da resposta dos alunos sobre meio ambiente, percebe-se, também, que alguns já possuíam uma consciência ambiental sobre a importância de se preservar a fauna e a flora, bem como jogar o lixo em locais adequados, a fim de, conforme o relato de um dos estudantes, "não deixar o meio ambiente triste" (Quadro 2). Além disso, a visão de uma aluna ao afirmar que não é possível viver sem o meio ambiente evidencia o quanto é possível criar uma tomada de consciência nas crianças mesmo nas fases iniciais.

Quadro 2: Respostas dos alunos sobre qual é a sua concepção acerca do meio ambiente.

\begin{tabular}{|c|c|}
\hline Sujeito & Fala transcrita \\
\hline Aluno A & "A natureza, como florestas, mares, rios, lagos." \\
\hline Aluno B & "Flor, árvores, mata, plantas." \\
\hline Aluno C & "Não jogar lixo no chão, não matar os animais, não matar as plantas." \\
\hline Aluno D & "Não jogar lixo na rua porque isso não pode fazer isso com o meio ambiente \\
porque ele fica muito triste."
\end{tabular}

Fonte: Autoria própria.

\section{Construção do jardim ecológico}

A construção do jardim ecológico foi realizada de forma bastante participativa. Os alunos demonstraram grande interesse e proatividade nas atividades práticas, muitos dos quais sugeriram as cores a serem utilizadas, bem como a disposição de alguns dos objetos e ornamentações criados (Figura 4). A partir dos resíduos sólidos, foi possível construir animais, flores e vasos de diversas cores e formas, sendo perceptível marcas da personalidade desses alunos na paisagem escolar (Figura 5). 


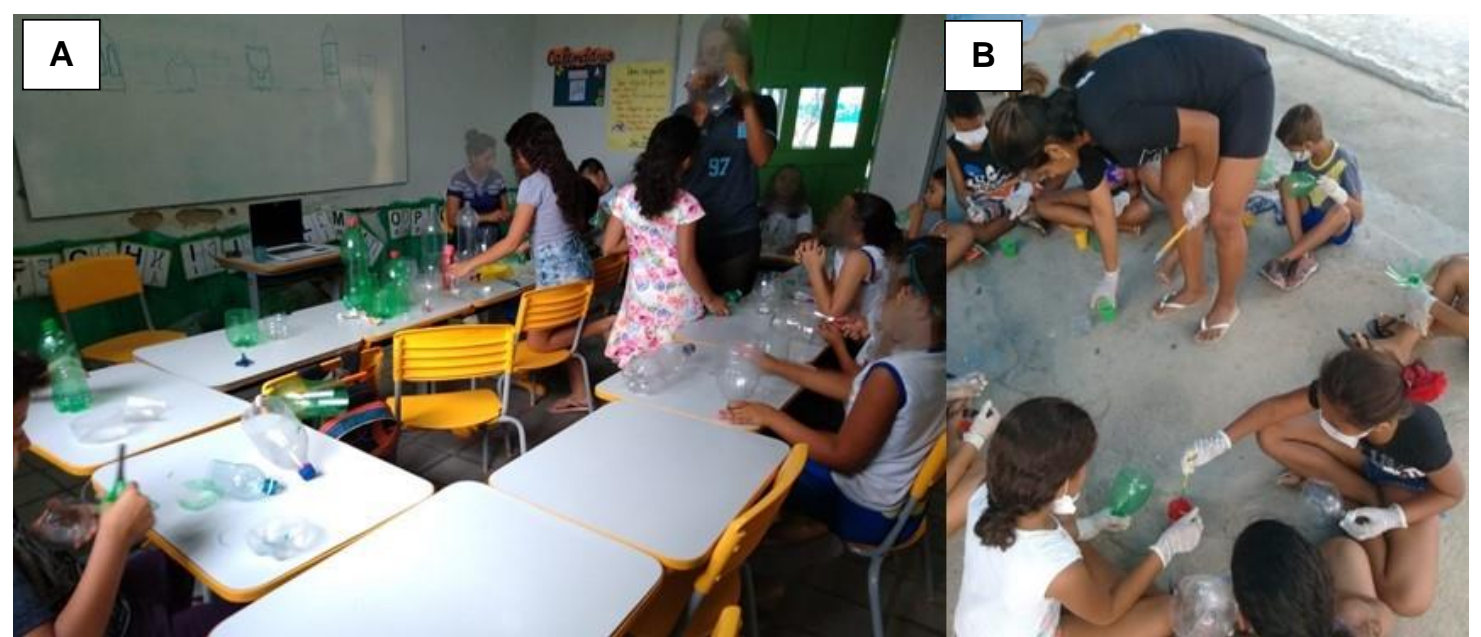

Figura 4: Participação coletiva dos alunos na construção dos ornamentos para o jardim ecológico a partir de resíduos sólidos. A: Oficina de criação dos moldes; B: Oficina de pintura.

Fonte: Autoria própria.

Além da ação dos alunos, houve também a participação coletiva dos funcionários da escola, tanto terceirizados como gestores e professoras. Os terceirizados forneceram os materiais necessários para a irrigação e montagem do jardim, bem como se dispuseram a auxiliar no acompanhamento do projeto. Dessa forma, o resultado obtido ao final das intervenções com a construção do jardim ecológico, a partir de materiais reutilizados, foi bastante satisfatório para alunos, escola e comunidade, uma vez que o ambiente, antes sem vida e sem atrativos (Figura 1), foi transformado em um local colorido e criativo (Figura 6).

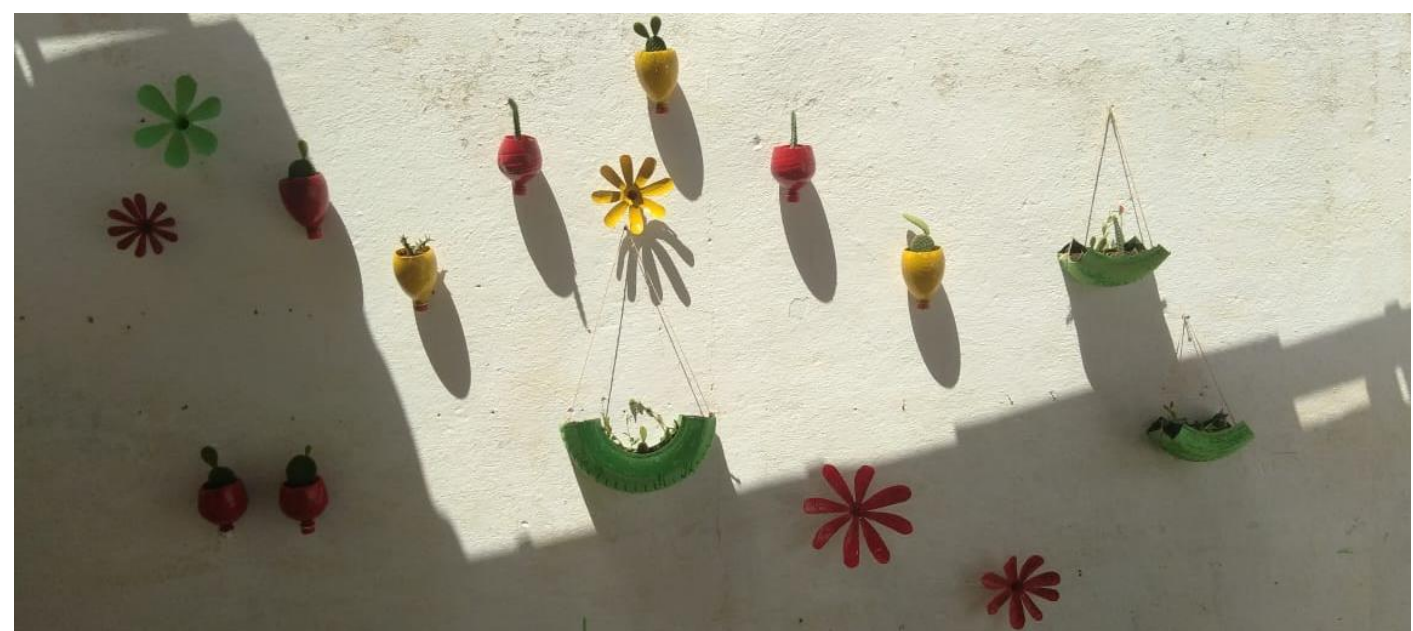

Figura 5: Ornamentações construídas pelos alunos com garrafas pet e pneus reutilizados. Foto retirada do corredor lateral da escola, próximo às salas de aula.

Fonte: Autoria própria. 


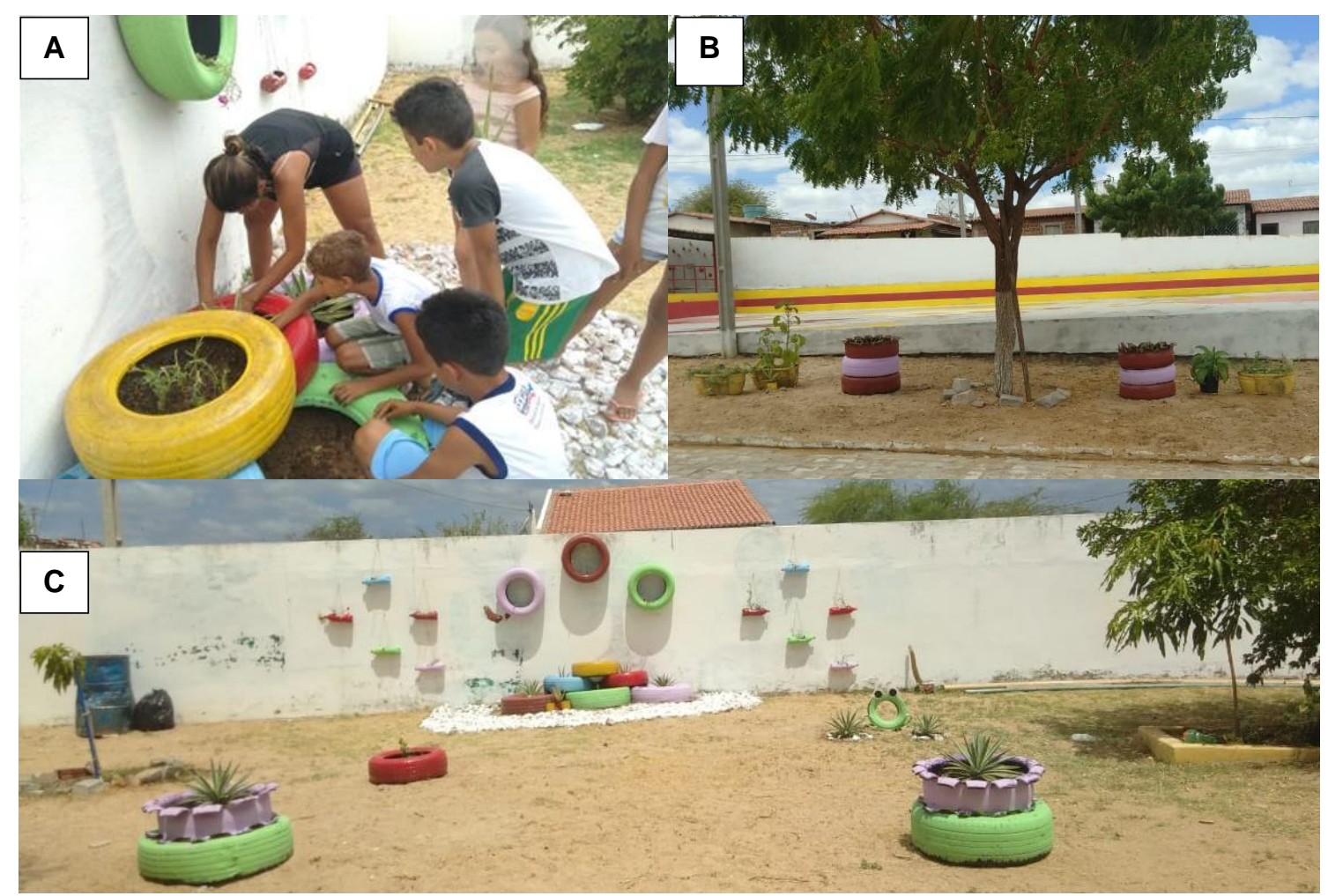

Figura 6: A: Plantio de algumas mudas; B: Vasos produzidos com pneus reutilizados ao longo do corredor de acesso às salas de aula; C: Vista frontal do jardim finalizado.

Fonte: Autoria própria.

As professoras, a diretora e os alunos fizeram bastantes registros fotográficos e compartilharam nas redes sociais. Essa divulgação foi importante para dar visibilidade às ações para outras escolas, bem como para a comunidade. Os alunos também ficaram responsáveis por zelar pela boa manutenção do jardim e das demais ornamentações.

Nas duas visitas realizadas após as intervenções, verificou-se que os alunos e funcionários continuaram bastante contentes com os resultados e que os espaços do jardim e demais ornamentações mantiveram-se bem cuidados (Figura 7). Os alunos se organizaram em grupos que ficavam responsáveis por cuidar das plantas, regar e acompanhar diariamente essas ações. A diretora informou que a realização do projeto a incentivou a fazer uma decoração e revitalização de outros espaços da escola. As professoras informaram que os alunos da turma impediam que os estudantes mais novos destruíssem o jardim, alertando-os quanto ao desperdício de água e repreendendo-os quando os viam jogando algum tipo de lixo em local inadequado. Em conversa com os discentes, alguns relataram que deixaram de jogar lixo no chão e que passaram a guardar na bolsa quando não encontravam uma lixeira por perto. Além disso, a partir de então, passaram a discernir as plantas que precisavam ser regadas das que não necessitavam, como as cactáceas e demais suculentas utilizadas no projeto, ressaltando o fato de que era importante preservar e cuidar da natureza. 


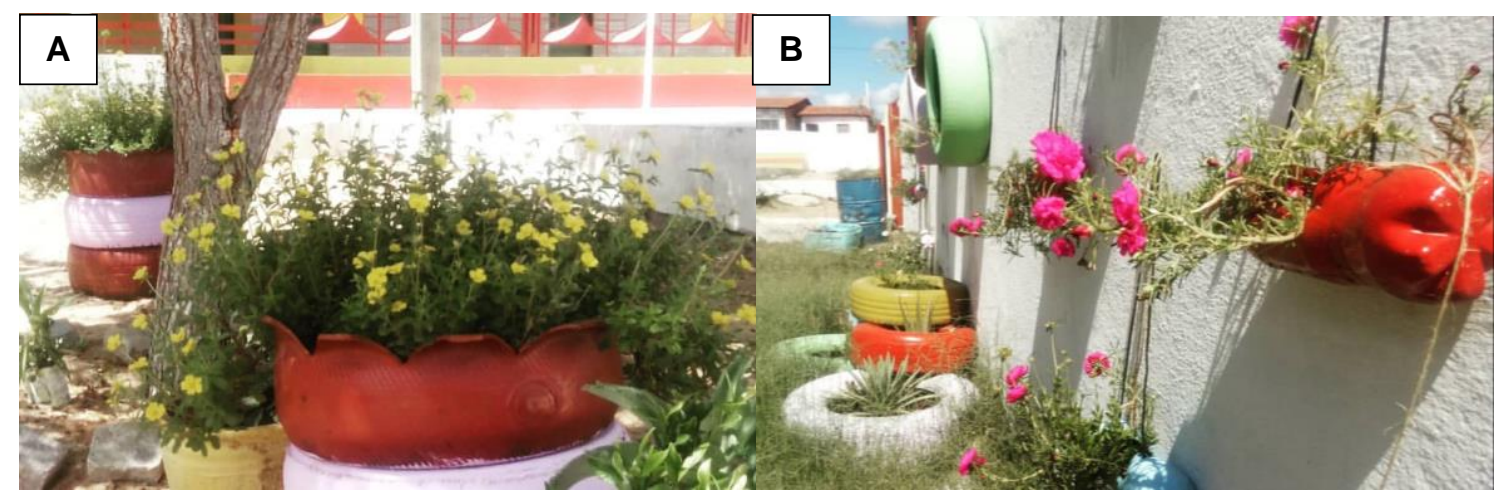

Figura 7: Jardim ecológico após três meses da sua finalização (março/2020), com as flores em evidência. A: Vasos do corredor de acesso às salas de aula; B: Jardim vertical da entrada.

Fonte: Autoria própria.

Segundo os professores e a diretora, a partir das fotografias divulgadas nas redes sociais, muitas pessoas entraram em contato, afirmando que acharam a escola bastante bonita e com mais vida. Verifica-se, portanto, que a realização deste estudo apresentou múltiplos benefícios, não somente para os alunos e a escola, mas para a comunidade como um todo, pois essa experiência pode servir como inspiração e exemplo para outras escolas adotarem a mesma iniciativa. Destarte, crianças funcionam como agentes multiplicadores, podendo levar as experiências positivas aprendidas para outros espaços (SILVA et al., 2018).

Uma das principais queixas dos docentes para desenvolver projetos de Educação Ambiental nas séries iniciais da escola é a falta de oferta de capacitação na área, bem como a carência de materiais oferecidos pela prefeitura e de recursos para viabilizar tais ações. Dessa maneira, muitos projetos são desenvolvidos por iniciativa e interesse próprio dos educadores (MOURA; MACHADO, 2017). Todavia, esta pesquisa evidencia que estabelecer parcerias com instituições de ensino do entorno da escola, como o IFRN/IP, é fundamental para que ações como esta possam ser realizadas em situações de escassez de recursos. Além disso, é possível trabalhar de forma contínua e não pontual, possibilitando o envolvimento da comunidade escolar de forma interdisciplinar. O educador, portanto, desempenha um papel importante na criação e recriação de ideias que possibilitem o aprendizado e a adoção de posturas sustentáveis sob uma nova perspectiva de ensino (STEIN, 2011).

Essa experiência permite refletir também sobre a importância da reutilização e ressignificação dos resíduos sólidos. A cultura das pessoas caracteriza seus hábitos de consumo e geração de lixo, mas também influencia sobremaneira a forma como elas lidam com a disposição desse lixo. Todo material que foi utilizado, se tivesse sido descartado inadequadamente, poderia provocar contaminação do solo e da água, proliferação de vetores de doenças, mau cheiro e poluição visual (MUCELIN; BELLINI, 2008). Em vez disso, foi possível transformar o que costumeiramente é visto como algo sem utilidade Revbea, São Paulo, v.16, № 1: 472-492, 2021. 
em um recurso para harmonia paisagística. É possível perceber, pois, que, com pouco recurso e através de parcerias, a mudança do ambiente escolar é factível.

\section{Análise do questionário de satisfação}

Os resultados evidenciaram que o projeto se mostrou bastante positivo e com ampla aceitação por parte dos alunos. A maioria dos sujeitos participantes do projeto, representada por 15 alunos (88\%), afirmou estar satisfeita ou muito satisfeita com a aplicação do projeto, ao passo que apenas $2(12 \%)$ afirmaram estarem indiferentes ou não gostarem do projeto (dados não apresentados). Os comentários dos alunos a respeito do resultado final da construção do jardim ecológico foram sobretudo positivos. Isso foi notado através de algumas frases opinativas feitas pelos alunos, tais como "Ficou incrível", "Gostei muito" e "Muito legal". Isso demonstra quão satisfeitos as crianças estavam com as intervenções. Além disso, quando indagados sobre quais atividades eles mais gostaram, 13 (76\%), 10 (59\%) e 9 alunos (53\%) afirmaram terem apreciado as abordagens dinâmicas, práticas e teóricas, respectivamente (Figura 8). Esses dados evidenciam a importância de se desenvolver projetos com a intervenção das próprias crianças nas escolas, as quais demonstram querer participar e colaborar com as atividades. Além disso, esses resultados reforçam que é fundamental a adoção de métodos lúdicos e dinâmicos no planejamento das atividades, as quais acabam sendo mais bem apreciadas pelos estudantes.

A ludicidade é uma característica fundamental do processo de ensinoaprendizagem, sobretudo nas séries iniciais do Ensino Fundamental, uma vez que desenvolve a criatividade, desperta a curiosidade e viabiliza formas de a criança explorar o mundo e estabelecer relações lógicas (KISHIMOTO, 2014). Ademais, a adoção de dinâmicas e brincadeiras proporciona maior vínculo entre o aluno e o professor, bem como cria laços duradouros que permanecem na memória da criança, o que auxilia no amadurecimento intelectual e contribui para que 0 aluno adquira prazer em aprender (RIOS; SILVA; 2018).

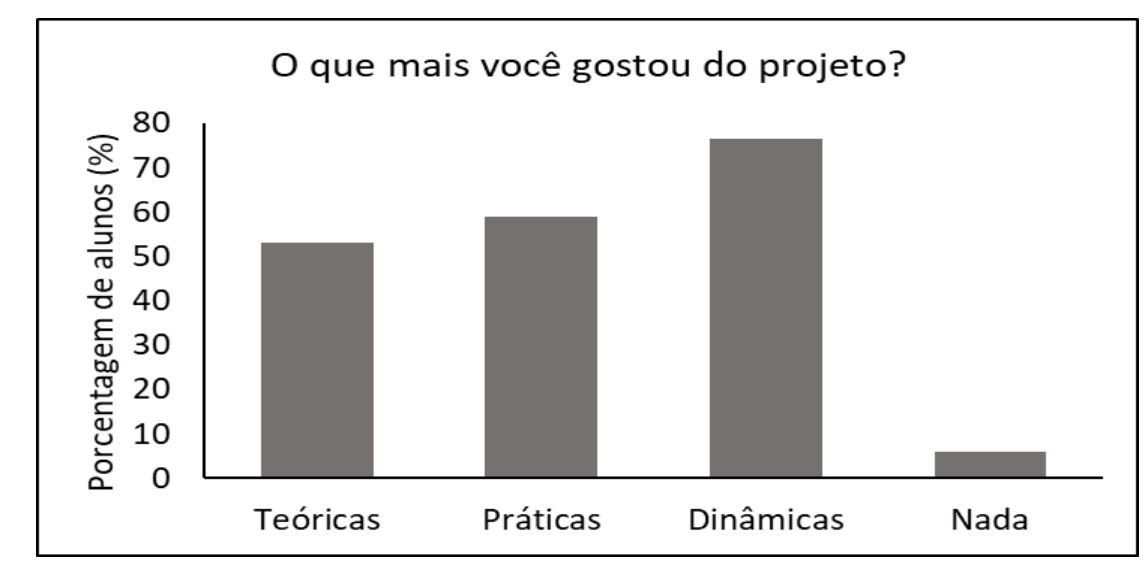

Figura 8: Abordagens do projeto mais bem apreciadas pelos alunos; $\mathrm{N}=17$.

Fonte: Autoria própria. 
Quando indagados sobre as temáticas que eles mais aprenderam, verificou-se que 13 (76\%), $9(53 \%)$ e $8(47 \%)$ alunos citaram os temas Educação Ambiental, meio ambiente e reciclagem, respectivamente (Figura 9). É possível perceber que, com as intervenções, os alunos conseguiram ter contato com assuntos com os quais não tinham muita familiaridade anteriormente, possibilitando, assim, agregar novas perspectivas ambientais para sua formação. A decisão de trabalhar esses temas nas séries iniciais da escola é fundamental para que os futuros cidadãos se interessem pelas questões ambientais, uma vez que nessa fase é possível haver uma melhor internalização desses assuntos na sua personalidade, possibilitando, assim, a adoção de posturas e atitudes sustentáveis (MEDEIROS et al., 2011).

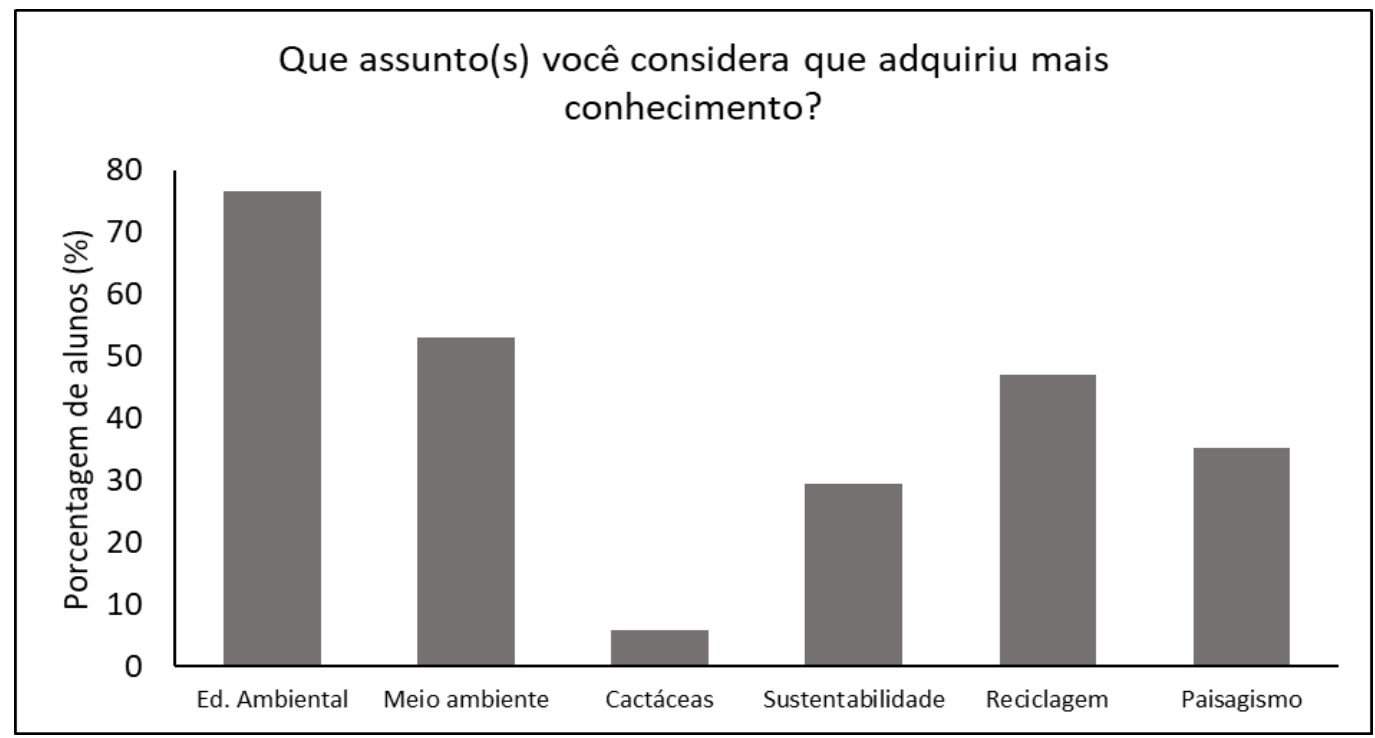

Figura 9: Temáticas que, segundo os alunos, mais contribuíram ao seu conhecimento; $\mathrm{N}=17$. Fonte: Autoria própria.

Ao serem questionados sobre a probabilidade de aplicarem em casa os conhecimentos adquiridos através do projeto, a maioria dos estudantes respondeu que seria muito provável (13 alunos; 76\%), evidenciando, assim, que não somente o projeto foi bem recepcionado, mas também despertou o interesse das crianças em terem tais atividades em seus domicílios (Figura 10, próxima página).

A adoção de hábitos sustentáveis e a construção de jardins ecológicos em casa são excelentes alternativas para diminuir a produção de lixo domiciliar e, portanto, evitar seus impactos negativos no ambiente. No momento em que os resíduos sólidos passam a ser vistos como matéria-prima para a confecção de objetos de grande valor utilitário, o ser humano começa a refletir sobre o real significado do lixo e sobre suas atitudes frente ao planeta (ASSAD, 2016). Dentre os diversos destinos alternativos possíveis para os resíduos sólidos, além da utilização em jardins ecológicos, como neste projeto, eles podem ser 
usados para confecção de brinquedos e jogos reciclados (ALVES; TRINDADE, 2014), objetos de ornamentação em casa e, inclusive, materiais didáticos para uso pedagógico (MEDEIROS, 2020).

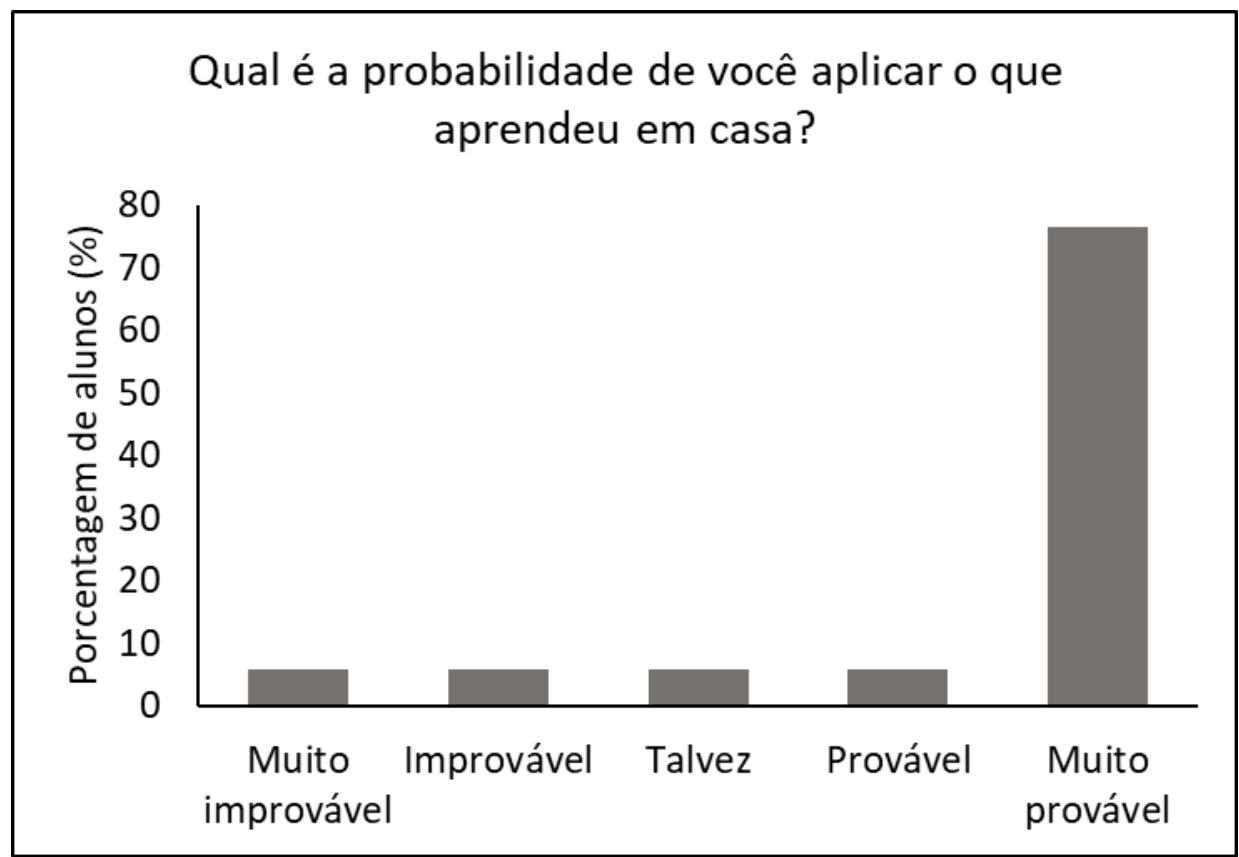

Figura 10: Respostas dos alunos a respeito da probabilidade de eles aplicarem em casa algo que aprenderam do projeto; $\mathrm{N}=17$.

Fonte: Autoria própria.

Muito embora os resíduos sólidos possam apresentar múltiplos usos em casa além do seu descarte com o lixo comum, o que se vê na prática é a total negligência das famílias em adotar posturas sustentáveis com o lixo doméstico (CARDOSO; CARDOSO, 2016). Se as crianças demonstram interesse em desenvolver essas atividades com os resíduos sólidos em casa, como foi possível perceber neste trabalho, por que ainda existe resistência em se adotar tais posturas sustentáveis nas residências? Segundo um estudo realizado por Poletto (2005), com crianças entre 7 e 10 anos em situação de vulnerabilidade social, apesar de os familiares favorecerem tempo e espaço para que elas brinquem nos lares, eles possuem pouco tempo para realizar e acompanhar atividades lúdicas com seus filhos. Além disso, a preferência por brinquedos industrializados e a baixa referência a brinquedos de criação artesanal sugerem que existem poucas oportunidades de a criança usar da criatividade em casa.

O que se evidencia na prática, portanto, é que muitas vezes a relação entre a criança, os pais e a escola é desarticulada, fazendo com que os ensinamentos advindos do âmbito escolar acabem não sendo levados para casa. Aliado a isso, culturalmente, as pessoas não apresentam proatividade para adotar posturas sustentáveis em suas residências por uma falta de 
incentivo governamental e midiático, além de carência de uma conscientização ambiental efetiva que garanta uma mudança de comportamentos (SECCHI et al., 2017). Isso acontece porque vivemos sob uma forte influência do capitalismo, que incentiva o consumismo além das necessidades (ZANIRATO; ROTONDARO, 2016) em detrimento da criação e recriação de objetos a partir de resíduos sólidos. Assim, segundo Costa e colaboradores (2018) "a melhor forma de se conscientizar a sociedade e o setor produtivo a respeito das complexidades e consequências dos resíduos sólidos exponencialmente advindos da cultura consumista é por intermédio da publicidade e, sobretudo, da Educação Ambiental, em todos os níveis de ensino".

\section{Conclusões}

Este estudo evidenciou que as intervenções propostas surtiram um efeito positivo nas crianças, conscientizando-as sobre a importância da adoção de uma postura sustentável e proativa na preservação do meio ambiente. Nossa ação visou ir além da análise do problema em questão, fazendo com que o pesquisador e os sujeitos da pesquisa fossem, de fato, atuantes na busca de soluções para os problemas que surgem no cotidiano constantemente. Essa atuação ativa permitiu que ocorresse um avanço no conhecimento e, consequentemente, uma reflexão da problemática em questão. Desse modo, notamos que o projeto contribuiu efetivamente para a mudança das áreas da escola a partir da criação de um jardim ecológico, que contou com o empenho das crianças, desde ideias personalizadas até a ajuda na prática, em que o próprio ambiente em torno da escola mudou.

A pesquisa possibilitou evidenciar que, a partir da EA, é possível superar $\mathrm{O}$ analfabetismo ambiental, podendo, assim, criar sociedades sustentáveis, cientes de que a convivência harmônica com o meio ambiente é a única maneira capaz de garantir a qualidade ambiental e a sobrevivência das gerações futuras (MEDEIROS et al., 2011).

Ademais, este trabalho reforça que ações como essa proporcionam uma grande disposição e despertam a curiosidade nas crianças em reutilizar resíduos sólidos para criar objetos com significado e transformar ambientes com sua personalidade. Para isso, é importante se utilizar da ludicidade para chamar a atenção das crianças para temáticas voltadas à preservação ambiental e, com o desenvolvimento de atividades práticas e dinâmicas, ser possível incentivar o aspecto da proatividade. Todavia, é importante salientar a importância de se desenvolver estudos futuros que visem investigar a articulação entre escola e família, a fim de garantir que as posturas e consciências incentivadas na escola sejam, de fato, internalizadas e transformadas em atitudes sustentáveis, bem como disseminadas para outros indivíduos, como os pais e familiares. 


\section{Referências}

ALVAREZ, I.A.; KIILL, L.H.P. Arborização, Floricultura e Paisagismo com Plantas da Caatinga. Informativo ABRATES, v. 24, n. 3, 2014.

ALVES, D.O.V.; TRINDADE, B. A confecção de brinquedos e jogos reciclados para conscientização dos problemas dos resíduos sólidos. Revista Eletrônica em Gestão, Educação e Tecnologia Ambiental, v. 18, n. 2, 2014.

ASSAD, L. Lixo: uma ressignificação necessária. Ciência e Cultura, v. 68, n. 4, 2016.

BARBOSA, L.M. Topofilia, Memória e Identidade na Vila do IAPI em Porto Alegre. Para Onde!? R. Progr. de Pós-Grad. em Geografia, v. 4, n. 2, 2010.

CARDOSO, F.C.I.; CARDOSO, J.C. O problema do lixo e algumas perspectivas para redução de impactos. Cienc. Cult., v. 68, n. 4, 2016.

CINQUETTI, H.S. Lixo, resíduos sólidos e reciclagem: uma análise comparativa de recursos didáticos. Educar em Revista, v. 1, n. 23, 2004.

COSTA, B.S.; DIZ, J.B.M.; OLIVEIRA, M.L. Cultura de consumismo e geração de resíduos. Revista Brasileira de Estudos Políticos, v. 1, n. 116, 2018.

DIAS, G. F. Educação Ambiental: princípios e práticas. 9a ed. São Paulo: Gaia, 2010.

EMER, A.A.; BORTOLINI, C.E.; ARRUDA, J.H.; ROCHA, K.F.; MELLO, N.A. Valorização da flora local e sua utilização na arborização das cidades. Synergismus scyentifica UTFPR, v. 1, n. 6, 2011.

FAGUNDES, J.F.; BANDEIRA, G.L.; SIQUEIRA, A.B.; NEIS, F.A.; KONFLANZ, T.L. Arborização e jardinagem na Escola Municipal de Ensino Fundamental Assis Brasil em Palmeira das Missões - RS. Revista Eletrônica em Gestão, Educação e Tecnologia Ambiental, v. 19, n. 2, 2015.

FREIRE, P. Conscientização: teoria e prática da libertação: uma introdução ao pensamento de Paulo Freire. $1^{\underline{a}}$ ed. São Paulo: Cortez \& Moraes, 1979.

GENGO, R.C.; HENKES, J.A. A utilização do paisagismo como ferramenta na preservação e melhoria ambiental em área urbana. R. gest. sust. ambient., v. 1, n. 2, 2013.

GHEDIN, E.; FRANCO, M.A.S. Questões de método na construção da pesquisa em educação. São Paulo: Cortez, 2008.

GUMY, G.; BOBROWSKI, R. A Percepção e a Importância das Áreas Verdes no Ambiente Escolar. In: PARANÁ. Secretaria de Estado da Educação. Superintendência de Educação. Os Desafios da Escola Pública Paranaense na Perspectiva do Professor PDE Produção Didático-pedagógica, v. 1, 2016. Disponível em: <http://www.diaadiaeducacao.pr.gov.br/portals/cadernospde/ pdebusca/producoes pde/2016/2016 artigo dtec unicentro gilmargumy.pdf >. Acesso em: 29 mai. 2020. 
IBGE. Instituto Brasileiro de Geografia e Estatística. Divisão regional do Brasil em mesorregiões e microrregiões geográficas. Biblioteca IBGE. 1: 44-47.

1990. Disponível em: <https://biblioteca.ibge.gov.br/visualizacao/livros/ liv2269 1.pdf>. Acesso em: 30 mai. 2020.

IBGE. Instituto Brasileiro de Geografia e Estatística. Cidades e Estados, 2019. Disponível em: <https://cidades.ibge.gov.br/brasil/rn/angicos/panorama>. Acesso em: 30 mai. 2020.

KISHIMOTO, T.M. Jogos infantis: O jogo, a criança e a educação. 18 ed. Petrópolis: Vozes, 2014.

LEAL, I.R.; SILVA, J.M.C.; TABARELLI, M.; LACHER J.R. Mudando o curso da conservação da biodiversidade na Caatinga do Nordeste do Brasil. Megadiversidade, v. 1, n. 1, 2005.

LINK, D.J.; ARAÚJO, L.E.B.; HILLING, C. Conscientização ambiental com alunos da educação infantil da Escola de Ensino Fundamental Kinderwelt de Agudo - RS. Monografias Ambientais, v. 6, n. 6, 2012.

MARTINE, G.; ALVES, J.E.D. Economia, sociedade e meio ambiente no século 21: tripé ou trilema da sustentabilidade? R. bras. Est. Pop., v. 32, n. 3, 2015.

MEDEIROS, A.B.; MENDONÇA, M.J.S.L.; SOUSA, G.L.; OLIVEIRA, I.P. A Importância da Educação Ambiental na escola nas séries iniciais. Revista Faculdade Montes Belos, v. 4, n. 1, 2011.

MEDEIROS, J.M.M. 2008. 200f. Visões de um Paisagismo Ecológico na Orla do Lago Paranoá. Dissertação (Mestrado em Arquitetura e Urbanismo) Curso de Pós-Graduação em Arquitetura e Urbanismo, Universidade de Brasília. Disponível em <https://repositorio.unb.br/bitstream/10482/4880/1/ Dissert JoseMarceloMMedeiros.pdf>. Acesso em: 30 mai. 2020.

MEDEIROS, L. R. Utilização de modelos táteis sustentáveis como alternativa no ensino de Química para alunos com deficiência visual. In: SÁ, R. O.; ALMEIDA; B. T. (Org.). Discursos Interdisciplinares por uma Educação Transformadora. $1^{\underline{a}}$ ed. Natal: FAMEN, v. 1, n. 1, 2020.

MEIRA, M.M.C.; SILVA, C.R.T.; CARVALHO, L.O.; RODRIGUES, M.A.; BRASIL, M.D.; SANTOS, P.A. A beleza seca: Aspectos do paisagismo no semiárido brasileiro. Mix Sustentável, v. 6, n. 1, 2017.

MORO, M.F.; WESTERKAMP, C.; MARTINS, F.R. Naturalization and potential impact of the exotic tree Azadirachta indica A.Juss. in Northeastern Brazil. Check List, v. 9, n. 1, 2013.

MOTA, A.; BARBOZA, K.G.; BOAS, J.Q.V.; SOUZA, T.C.; MINEO; M.F. O conceito de jardins sustentáveis aplicado ao paisagismo urbano de forma a envolver entidades públicas, privadas e cidadãos: um estudo de caso do município de Uberaba, Minas Gerais. Anais do IV Congresso Brasileiro de Gestão Ambiental, 2013. Disponível em: <https://www.ibeas.org.br/congresso/ Trabalhos2013/VI-058.pdf>. Acesso em: 28 mai. 2020. 
MOURA, P.C.; MACHADO, M.E.R. O meio ambiente na Educação Infantil: Um estudo de campo nas escolas públicas de educação infantil da rede municipal de Santana do Livramento. Anais do IX Salão Internacional de Ensino, Pesquisa e Extensão, 2017. Santana do Livramento/RS, 2017. Disponível em: $<$ http://dspace.unipampa.edu.br/bitstream/riu/2916/1/Moura $\mathrm{Pa}$ ola CastroO\%20meio\%20ambiente\%20e\%20a\%20educacao\%20infantil.pdf>. Acesso em: 02 jun. 2020.

MUCELIN, C.A.; BELLINI, M. Lixo e impactos ambientais perceptíveis no ecossistema urbano. Sociedade \& Natureza, v. 20, n. 1, 2008.

POLETTO, R.C. A ludicidade da criança e sua relação com o contexto familiar. Psicologia em Estudo, v. 10, n. 1, 2005.

POLLI, F.G.; SOUZA, A.A. Relação de consumo e meio ambiente: Proposta de responsabilização efetiva das fabricantes e comerciantes de bens e serviços pelo recolhimento dos resíduos sólidos dos produtos comercializados. Revista Eletrônica do Curso de Direito, v. 8, n. 1, 2013.

REIGOTA, M. O que é Educação Ambiental. $2^{\underline{a}}$ ed. São Paulo: Brasiliense, 2012.

RIBEIRO, A.C.S.; SOARES, G.L.; VILHENA, T.F.P.; MUNHOZ, J.M.; STEFENON, V.M. Qualidade de vida no ambiente escolar como componente da formação do cidadão: Desejos e carências no espaço físico. Monografias Ambientais, v. 8, n. 8, 2012.

RIOS, P.P.S.; SILVA, T.O. O lúdico nas séries iniciais do Ensino Fundamental: a brincadeira deve continuar. Anais do V Congresso Nacional de Educação, 2018. Olinda, PernambucoCampina Grande: Realize Eventos, 2018.

SAFT, D.M.; PERES, P.E.C.; LINK, D.; NISHIJIMA, T. Paisagismo no Pátio Escolar: A Arte como Instrumento de Sensibilização à Educação Ambiental. Monografias Ambientais, v. 2, n. 2, 2011.

SALVIATÍ, E. Tipos vegetais aplicados ao paisagismo. Paisagem e Ambiente, v. 1, n. 5, 1993.

SANTOS, R. 2009. 29f. A Importância do Paisagismo quanto a Promoção de Qualidade de Vida. Monografia (Graduação em Ciências Biológicas) - Curso Graduação em Ciências Biológicas, Faculdade Assis Gurgacz. Disponível em: $<$ https://www.fag.edu.br/upload/graduacao/tcc/522a518a0a3fd.pdf >. Acesso em: 28 mai. 2020.

SECCHI, K.; VIEIRA, F.F.; RAMOS, L.B. O consumismo e a mídia: uma perspectiva psicológica. Barbarói, v. 1, n. 49, 2017.

SILVA, A.D.; SILVA, F.H.M.; MAIA, S.Z.; LEITE, Y.F.M.M. A Educação Ambiental e a criança: uma relação multiplicadora. Anais do $\mathrm{V}$ Congresso Nacional de Educação, 2018. Olinda, Pernambuco. Campina Grande: Realize Eventos, 2018. 
SILVA, S.; FERREIRA, E.; ROESLER, C.; BORELLA, D.; GELATTI, E.; BOELTER, F.; MENDES, P. Os 5 R's da sustentabilidade. Anais do V Seminário de Jovens Pesquisadores em Economia \& Desenvolvimento. 2017. Santa Maria, Rio Grande do Sul. Universidade Federal de Santa Maria, 2017.

STEIN, D.S. Ações educativas ambientais no cotidiano de uma escola municipal de Santa Maria, RS. Monografia (Especialização em Educação Ambiental) - Curso de Pós-Graduação em Educação Ambiental, Universidade Federal de Santa Maria. Disponível em: <https://repositorio.ufsm.br/handle/ 1/288>. Acesso em: 22 mai. 2020.

THIOLLENT, M. Metodologia da pesquisa-ação. $2^{\underline{a}}$ ed. São Paulo: Cortez, 1986.

ZANIRATO, S.H.; ROTONDARO, T. Consumo, um dos dilemas da sustentabilidade. Estudos avançados, v. 30, n. 88, 2016.

ZEA, J.D.; BARROSO, R.F.; SOUTO, P.C.; SOUTO, J.S. Levantamento e diversidade da arborização urbana de Santa Helena, no semiárido da Paraíba. Agropecuária Científica no Semiárido, v. 11, n. 4, 2015. 